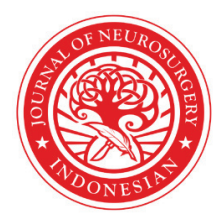

\title{
Isolated foot drop secondary to severe stenosis of spondylosis lumbar spine: case reports
}

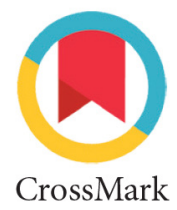

\author{
Farid Yudoyono ${ }^{1,2^{*}}$, Nasofi Tri Ramdhani ${ }^{1}$, Dewi Pratiwi ${ }^{1}$, Hendra ${ }^{1}$, Deasy Herminawaty ${ }^{1}$
}

${ }^{1}$ Neurospine and Pain Center, Santosa Hospital Kopo, Bandung, Jawa Barat.

${ }^{2}$ Department of Neurosurgery, Hasan Sadikin Hospital, Faculty of Medicine, Universitas Padjadjaran, Bandung, Jawa Barat.
*Corresponding author: Farid Yudoyono; Department of Neurosurgery, Hasan Sadikin Hospital, Faculty of Medicine, Universitas Padjadjaran, Bandung, Jawa Barat;

faridense@gmail.com

Received: 2019-05-10

Accepted: 2019-07-15

Published: 2020-04-01

\section{ABSTRACT}

Background: The purpose of this study was to report the clinical features and prognostic factors of surgical outcome of foot drop caused by severe stenosis of spondylosis lumbar.

Case presentation: We reported two cases of patients were identified with isolated foot drop caused by severe stenosis of spondylosis lumbar spine.

Conclusion: Our case report findings that duration of symptom to surgery, the severity of nerves compression are the poor prognostic factors, decompressive surgery was effective in terms of motoric outcome.

Keywords: decompressive surgery, foot drop, spondylosis

Cite This Article: Yudoyono, F., Ramdhani, N.T., Pratiwi, D., Hendra., Herminawaty, D. 2020. Isolated foot drop secondary to severe stenosis of spondylosis lumbar spine: case reports. Indonesian Journal of Neurosurgery 3(1): 1-3. D0I: 10.15562/ijn.v3i1.64

\section{INTRODUCTION}

Foot drop (FD) is a sign of a neuromuscular disorder characterized by difficulty in performing dorsiflexion of the ankle and toes. Spondylosis refers to degenerative changes in the lumbar spine, including disc herniation, osteophyte, thickening of the ligamentum flavum and spinal stenosis. Spondylosis is a common etiology for low back and leg pain., ${ }^{1,910} \mathrm{FD}$ is a debilitating symptom secondary to lumbar spondylosis. FD occurs unilaterally or bilaterally and associated with low back and leg pain. The common caused of FD include lower motor neuron disorders (plexopathy, radiculopathy or mononeuropathies of the deep peroneal, common peroneal, or sciatic nerves) and upper motor neuron disorders. ${ }^{1,2,8}$ In this study, we report two patients with isolated FD caused by lower motor neuron disorder secondary from severe stenosis of spondylosis lumbar spine.

All patients underwent nerve roots decompression and posterolateral lumbar fixation (PLF) with pedicle screw instrumentation by the same spinal neurosurgeon. Under general anaesthesia, patients were placed prone. After laminectomy of parts of inferior and superior laminae, the degenerated ligamentum flavum intervertebral disks were removed from one side. Bilateral pedicle screw fixation was then inserted on the affected levels. There were no serious postoperative complications.

\section{CASE 1}

A 64-year-old man presented with a one-year history of bilateral foot weakness and numbness along the dorsum of her right foot and anterolateral aspect of the lower limb. He also described a pinching pain behind the medial aspect of the right knee. There were no complaints of bowel or bladder incontinence or saddle paresthesia. The patient reported no recent trauma or previous neurological problems. The neurological findings were weakness in bilateral dorsiflexion $G 1 / 5$, ankle eversion $G 1 / 5$ and toe extension $G$ 1/5 (Figure 1). Decreased sensation in the bilateral anterolateral calf, dorsolateral aspect of the foot and webspace between the first and second toes, and dragging of the bilateral foot during gait analysis, with impaired dorsiflexion on heel strike. The patient still had decreased sensation but had an improvement in motor strength G 2/5 on outpatient clinic visit within six months after surgery with a multidiscipline approach.

Magnetic resonance imaging (MRI) showed severe bilateral stenosis at the L3-4-5 level and lateral stenosis on both sides of L3-4-5. Furthermore, type III Modic changes were also observed showing spondylosis (Figure 2). Patients underwent nerve roots decompression and posterior lumbar fixation with pedicle screw instrumentation.

\section{CASE 2}

A 54-year-old woman with a one-year history of 


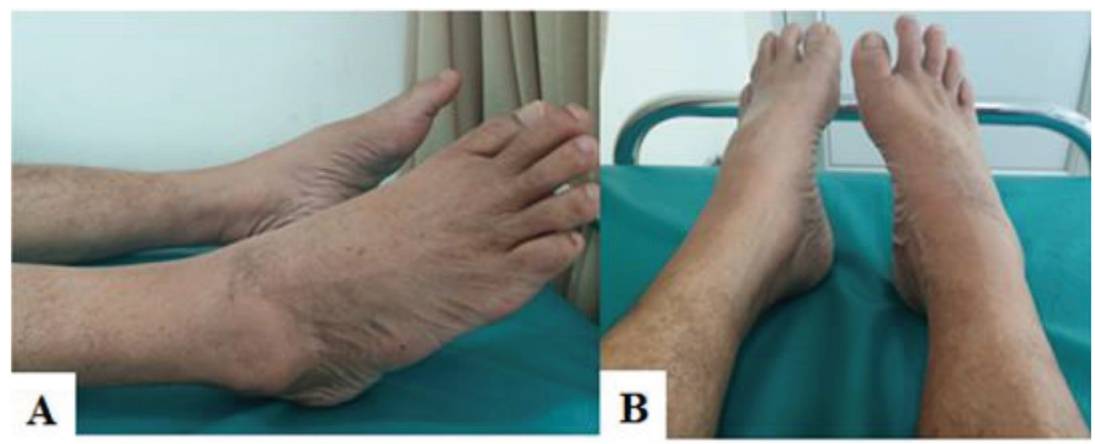

Figure 1. Clinical lateral view (A) and AP view (B) of weakness in bilateral dorsiflexion, ankle eversion and toe extension

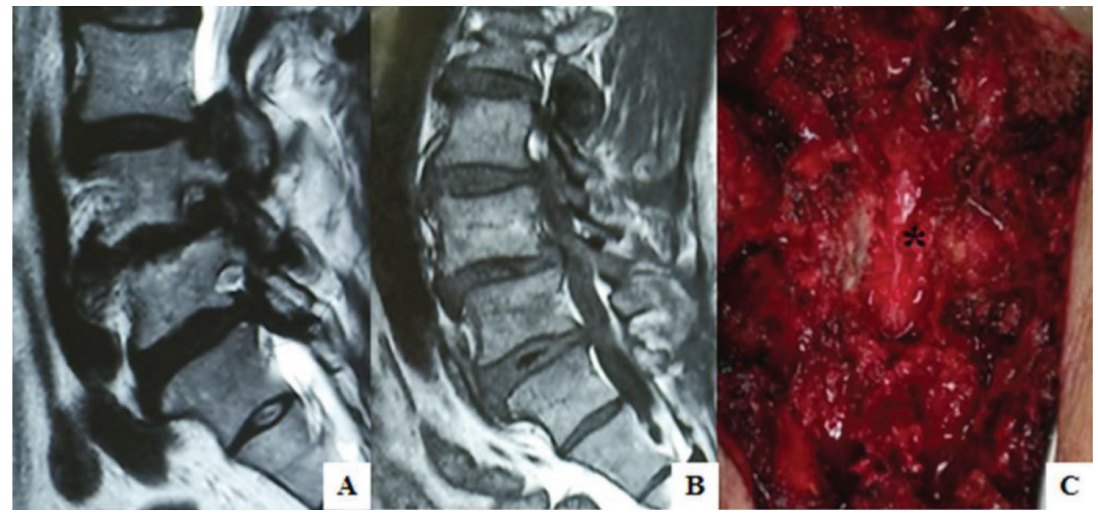

Figure 2. T2W1 (A) and T1W1 MRI (B) showing severe stenosis at L3-4-5 level and type II Modic changes, (C) Intraoperative view showed thickening of ligamentum flavum and facet hypertrophy (asterix).

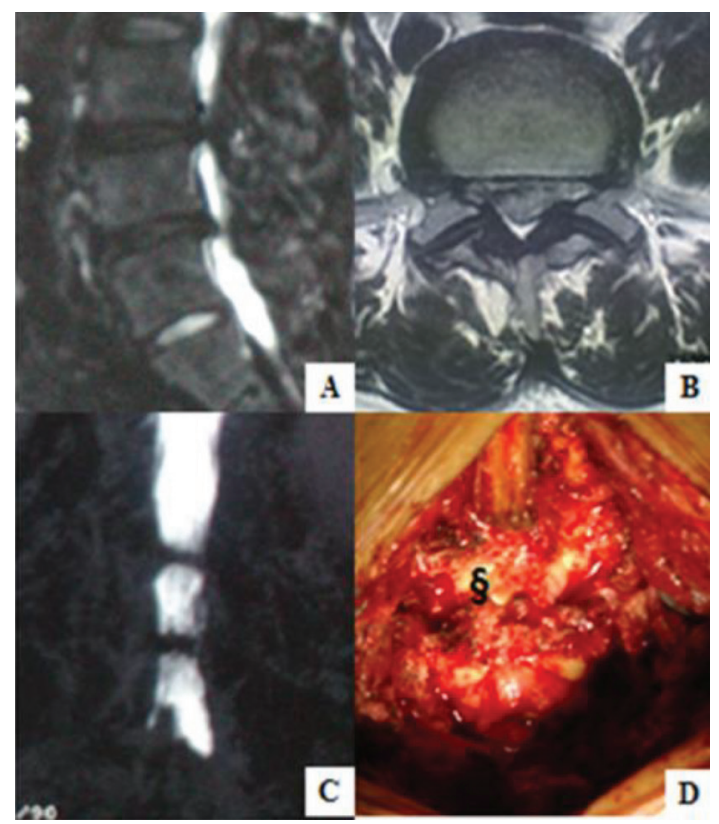

Figure 3. T2W1 MRI (A) sagittal and (B) axial view showed severe stenosis at the L3-4 level and type I Modic changes, (C) Myelography showed complete CSF block level L3-4, (D) Intraoperative view showed thickening of ligamentum flavum and epidural scar (double section) left foot weakness and numbness along the dorsal of his right foot and anterolateral aspect of the lower limb. She also described pain in the leftback radiating to the dorsal foot. There were no complaints of bowel or saddle paresthesia but mild bladder incontinence. The patient-reported a history of trauma before experiencing neurological problems. The neurological findings were weakness in left dorsiflexion (G3/5), ankle eversion (G3/5) and toe extension (G3/5), and decreased sensation in the left anterolateral calf, dorsolateral aspect of the foot and webspace between the first and second toes. The patient still experienced a decrease in sensation, but the motor strength had improved $G$ $4 / 5$ within six months after surgery on OPD visit with a multidiscipline approach.

MRI showed bilateral stenosis at the L4-5 level and lateral stenosis on both sides of L4-5 and CSF block on myelogram. Furthermore, Type III Modic changes were also observed showing spondylosis.

\section{DISCUSSION}

The prognosis, prevalence of associated neurological findings and the outcomes of FD were not well described in the previous study. FD is often caused by lower motor neuron disease. Patients with FD associated with lower back pain have a pathological location in the lumbar region. In other cases, FD might clinically be related to upper motor neuron abnormalities..$^{2-4,8}$

FD associated with degenerative spinal disorders is often accompanied by low back or radiating pain. In a previous study, all patients suffering from FD experienced low back pain and spread of pain. A previous study revealed that the recovery rates were $>80 \%$, with most patients making a complete recovery and the prognosis is still a debate among spinal surgeons. ${ }^{5}$

A study conducted by Aono et al. on 46 patients with FD found that more than half patients suffer from short-term pain and the others experience no pain..$^{1-3}$ The cure rate of FD depends on the duration of nerve compression and the characteristics of the patient. Younger age have higher hopes of recovery and decompression laminectomy can accelerate improvement in FD. ${ }^{3,6}$

The severity of compressed nerve roots suggests that the common peroneal nerve, which controls the tibialis anterior, also consists fibers from L4-S1 roots. Further neuroanatomical and electroneurophysiology studies are necessary. ${ }^{1}$ The duration of weakness was an important predictor for recovery. This is important as previous studies have reflected that preoperative motor strength influences outcome. , $^{3,5,6}$

Several studies showed decompressive surgery 
was an effective method to treat foot drop caused by spondylosis lumbar, although the sensory and motor functions of the spinal roots were difficult to recover after injured..$^{3,5,7,9}$ All cases in this study were chronic spondylosis disorders of the lumbar spine; thus, the healing process lasts longer and requires multidisciplinary treatment.

\section{CONCLUSION}

Isolated foot drop is very rare, often affecting the lower lumbar. The duration of symptom and complexity of the nerve compression are the poor prognostic factors. Younger age has a higher recovery rate. Decompressive surgery was effective in term of motoric improvement.

\section{CONFLICT OF INTEREST}

There is no potential conflict of interest relevant to this article reported.

\section{FUNDING}

No specific grant was provided for this article.

\section{AUTHORS' CONTRIBUTIONS}

All authors took part in the design of the study, literature review and writing the manuscript.

\section{REFERENCES:}

1. Liu K, Zhu W, Shi J, Jia L, Shi G, Wang Y, Liu N. Foot drop caused by lumbar degenerative disease: clinical features, prognostic factors of surgical outcome and clinical stage. PLoS ONE. 2013; 8(11): 1 - 6: e80375. DOI: 10.1371/ journal.pone.0080375.
2. Robles LA. Metachronous bilateral painless foot drop secondary to spinal stenosis: case report. Cureus. 2018; 10(3): 1 - 5: e2276. DOI: 10.7759/cureus.2276.

3. Takenaka S, Aono H. Prediction of postoperative clinical recovery of drop foot attributable to lumbar degenerative diseases, via a Bayesian network. Clin Orthop Relat Res. 2017; 475: 872 - 880. DOI: 10.1007/s11999-016-5180-x.

4. Bhargava D, Sinha P, Odak S, Tyagi A, Towns G, Pal D. Surgical outcome for foot drop in lumbar degenerative disease. Global Spine J. 2012; 2: 125 - 128. DOI: 10.1055/s0032-1326947.

5. Ghahreman A, Fercha RD, Raob P, Chandranb N, Shadboltc B. Recovery of ankle dorsiflexion weakness following lumbar decompressive surgery. Journal of Clinical Neuroscience. 2009; 16(8): 1024 - 1027. DOI: 10.1016/j. jocn.2008.10.017.

6. Girardi FP, Cammisa FP Jr, Huang RC, Parvataneni HK, Tsairis P. Improvement of preoperative foot drop after lumbar surgery. J Spinal Disord Tech. 2002; 15: 490 - 494. DOI: 10.1097/00024720-200212000-00010.

7. Kim HS, Kim HS, Kim SW, Shin H. Sudden foot drop caused by foraminal gas pseudocyst. J Korean Neurosurg Soc. 2011; 49 : 384 - 386. DOI: 10.3340/jkns.2011.49.6.384.

8. Kim KW, Park JS, Koh EJ, Lee JM. Cerebral infarction presenting with unilateral isolated foot drop. $J$ Korean Neurosurg Soc. 2014; 56(3) : 254 - 256. DOI: 10.3340/ jkns.2014.56.3.254.

9. Tsujimoto R, Abe Y, Arima K, Nishimura T, Tomita M, Yonekura $\mathrm{A}$, et al. Prevalence of lumbar spondylosis and its association with low back pain among communitydwelling Japanese women. BMC Musculoskeletal Disorders. 2016; 17(493): 1 - 6. DOI 10.1186/s12891-016-1343-x.

10. Middleton K, Fish DE. Lumbar spondylosis: clinical presentation and treatment approaches. Curr Rev Musculoskelet Med. 2009; 2(2): 94 - 104. DOI: 10.1007/ s12178-009-9051-x.

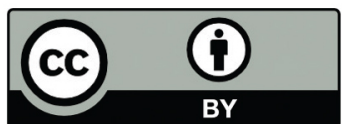

This work is licensed under a Creative Commons Attribution 